\title{
Clinico-Demographic Profile of Covid-19 Patients Admitted in COVID- HDU and its Association with Conjunctivitis
}

\author{
Pragya Singh Basnet ${ }^{1}$, Deepa Sharma ${ }^{2}$, Shravya Singh Karki², Sauhaida Karki², \\ Hira Lal Bhandari', Durga Shrestha ${ }^{3}$ \\ ${ }^{1}$ Department of Ophthalmology, Rapti Academy of Health Sciences, Dang, Nepal \\ ${ }^{2}$ Department of Research, Rapti Academy of Health Sciences, Dang, Nepal \\ ${ }^{3}$ Department of Information Technology, Rapti Academy of Health Sciences, Dang, Nepal
}

\section{ABSTRACT}

\begin{abstract}
Introduction: The outbreak of coronavirus diseases 2019 (Covid-19) caused by SARS-COV-2 which started in Wuhan china led to an alarming level of spread and severity. In Nepal, the first case of COVID-19 was reported on 23.1.2020 and has become a global health crisis since then. The clinical presentation and outcome of patients with COVID-19 have been variable in different countries and therefore it is important to analyze as well as document the clinical behaviors of this disease in the local population so we have reported the clinic-epidemiological profile, outcome, and its association with conjunctivitis during the second wave of this pandemic which hit Nepal badly hoping this study will be helpful to tackle the future surges of COVID-19 as well.
\end{abstract}

Materials and Methods: This was a prospective, single-center study where the data regarding epidemiology, demography, common clinical presentation as well as management and outcome of COVID-19 Patients were retracted and analyzed.

Results: A total of 238 COVID-Positive patients were admitted out of which $60 \%$ were male and $39.9 \%$ people belonged to Dang valley itself with dyspnea (67.2\%) was the commonest symptoms followed by fever in $59.7 \%$ of patients. Out of these patients 9 patients presented with ocular symptom conjunctivitis.

Conclusions: Mild conjunctivitis manifesting as conjunctival congestion is common and one of the major ocular manifestations in COVID -19 positive patients.

\section{Correspondence:}

Dr. Pragya Singh Basnet, MD

Rapti Academy of Health Sciences, Dang, Nepal

ORCID ID: 0000-0001-7698-2352

Email: pragyabasnet79@gmail.com

Submitted: $1^{\text {st }}$ November 2021 Accepted: $9^{\text {th }}$ December 2021

Source of Support: None Conflict of Interest: None

Citation: Basnet PS, Sharma D, Karki SS, Karki S, Bhandari HL, Shrestha D. Clinico-Demographic Profile of Covid-19 Patients Admitted in COVIDHDU and its Association with Conjunctivitis. NMJ 2021;4(2):482-4. DOI 10.3126/nmj.v4i2.41492

Key words: Conjunctivitis; COVID-2019; Pandemic; Red-eye

\section{INTRODUCTION}

The coronavirus disease 2019 (COVID-19) has emerged as a severe pandemic, claiming more than 0.8 million lives worldwide between December 2019 till August 2020. ${ }^{1}$ Viral analysis of the outbreak of SARS showed that bats are the natural reservoir for SARS-COVs. ${ }^{2}$ As societies around the world begin to reopen after many months of lockdown a worrying shift is emerging in the demography of Covid-19 cases towards individuals aged younger than 40 years. According to the analysis of 6 million cases between February and July 2020, the number of infected people aged 15-24 years. increased from $4.5 \%$ to $15 \%$ possibly resulting from a combination of increased socializing 
in younger age groups and reversion to previous routines. ${ }^{3}$ SARS$\mathrm{COV}$ - is thought to be transmitted from person to person mainly through respiratory droplets as close contacts. ${ }^{4}$ Patients infected with coronavirus SARS-COV-2 have an incubation period of 3-14 days with a mean period of 5 days the most common symptom of COVID-19 include fever, cough other symptoms include taste change, headache, abdominal pain, diarrhea, G.I bleeding. ${ }^{5}$ The ocular surface is exposed to the outside environment which many become a potential gateway for pathogens such as viruses to invade the human body. ${ }^{6}$ More over ACE-2 is a cellular receptor for SARS - Cov 2 which has been detected in human conjunctiva epithelia. ${ }^{7}$ Although the incidence of conjunctivitis is low, studies have shown that SARS-COV-2 has shown a capacity to use the eye as a portal of entry and cause ocular disease.

The majority of the population contracting coronavirus are asymptomatic but a significant number of patients experience fever, cough, headache, malaise, has loss of smell and taste and a minority of patients also experience red-eye as well but not many studies have been done to prove the relationship of corona-virus with conjunctivitis.

\section{MATERIALS AND METHODS}

This was a prospective, single-center study where the data regarding epidemiology, demography, common clinical presentation as well as management and outcome of COVID-19 patients admitted in tertiary care hospitals in western Nepal was evaluated. Data collection was done from 14 ${ }^{\text {th }}$ April 2021 till $30^{\text {th }}$ June 2021. The information was collected on a pre-designed Performa which included patients' demographic profiles, clinical presentations, and outcomes as per treatment by trained doctors. The study included 238 laboratory-confirmed Covid-19 affected individuals and it was approved by the institutional review committee. Data analysis was done in SPSS Software 17.

\section{RESULTS}

Total 238 patients were admitted to the HDU of Rapti Academy of Health Sciences. Among the study population, 226 patients were from Dang followed by 4 patients from Pyuthan, Rolpa, and Salyan which are the neighboring areas of Dang valley. Among 238 patients, $145(60.1 \%)$ were male and $95(39.9 \%)$ were female. Regarding age group, the most common age group was 41-65 years ( 78 patients) followed by 46 patients in the age group $19-45$ years and 17 patients were 65 years and older there were $95 \%$ female patients in females also the most common age group was 41-65 years (52 patients) followed by 22 patients in the age group 19-40 years.

Table 1 depicts the frequency of various signs and symptoms among the study population. Dyspnoea was the most common symptom in 160 patients (67.2\%) followed by fever in 192 patients $(59.7 \%)$ with cough in 101 patients $(42.4 \%)$. Other symptoms were diarrhea, myalgia, and headache. Reading the red-eye about 9 patients among the 238 patients had this ocular manifestation which comprised of $3.8 \%$ by which we can assume that although conjunctivitis could be one of the manifestations of Covid but not a common symptom of Covid 19. The average length of hospital stay was $5.93 \pm 4.52$ days among the study population. Determining factor for the length of hospital stay was not conjunctivitis.
Table 1: Signs and symptoms profile among the study population $(\mathbf{n}=\mathbf{2 3 8})$

\begin{tabular}{ll}
\hline Symptom Profile & Frequency n(\%) \\
\hline Fever & $142(59.7)$ \\
\hline Cough & $101(42.4)$ \\
\hline Dyspnea & $160(67.2)$ \\
\hline Diarrhea & $5(2.1)$ \\
\hline Myalgia & $14(5.9)$ \\
\hline Headache & $13(5.5)$ \\
\hline Red-eye & $9(3.8)$ \\
\hline
\end{tabular}

The outcome of the disease process among the study population is tabulated in table 2. 170 patients $(71.4 \%)$ were cured and discharged whereas $34(14.3 \%)$ were referred to a higher center for critical care management. All the patients $<18$ years of age survived, whereas $12(34.28 \%)$ patients ages $>65$ years died of COVID-19 (Table 3).

Table 2: Outcome of COVID-19 patients during the study period

\begin{tabular}{lll}
\hline & Frequency & Percent \\
\hline Cured & 170 & 71.4 \\
Referred & 34 & 14.3 \\
Death & 34 & 14.3 \\
Total & 238 & 100.0
\end{tabular}

Table 3: Outcome of COVID-19 patients according to the age -group

\begin{tabular}{lllll}
\hline Age Group & Cured & $\begin{array}{r}\text { Patient status } \\
\text { Referred }\end{array}$ & Death & Total \\
\hline$<\mathbf{1 8}$ years & 5 & 0 & 0 & 5 \\
\hline $\mathbf{1 9 - 4 0}$ years & 54 & 5 & 9 & 68 \\
\hline $\mathbf{4 1 - 6 5}$ & 91 & 26 & 13 & 130 \\
\hline$>\mathbf{6 5}$ years & 20 & 3 & 12 & 35 \\
\hline Total & $\mathbf{1 7 0}$ & $\mathbf{3 4}$ & $\mathbf{3 4}$ & $\mathbf{2 3 8}$ \\
\hline
\end{tabular}

\section{DISCUSSION}

A study conducted in India by Sonil et.al. ${ }^{8}$ showed the median age of patients was 33.5 years and male patients comprised $66 \%$ in comparison to $48 \%$ female patients. Similarly, a study done in north India by Mohan et. al. ${ }^{9}$ regarding the clinic-demographic profile of patients admitted in a tertiary care center showed that out of 144 patient mean age was $40.1 \pm 13.1$ years with $93 \%$ males which is similar to our result where we also have male preponderance and the common age group was 41 - 65 years. COVID-19 hit this age group more commonly as this in the most productive group and the group to socialize more as compared to the other age group. A study by $\mathrm{H}$ Agrawal et. al. ${ }^{10}$ on assessment on impact of COVID-19 infection in a gender-specific manner suggested that male patients were more likely to be affected by COVID-19 because of a higher rate of smoking and the role of testosterone which is immunosuppressive could be the result of higher incidence of COVID-19 in the male gender. A study in Northeast India showed the median time from the time of admission in the hospital to discharge was about 8 days. ${ }^{11}$ Our study showed the mean length of the hospital towards 5.93 days.

A study by Chen et. al. ${ }^{11}$ in china regarding ocular manifestation and clinical characteristics of 535 cases of COVID-case in Wuhan china showed 27 patients $(5 \%)$ presented with conjunctival 
congestion and the most common clinical symptom were fever, cough, and fatigue they suggested that frequent hand-eyes contact may be the risk factor for conjunctiva congestion in COVID-19 patients. An observational study reported an apparent protective effect against SARS-COVID-2 transmission from routinely wearing spectacles for more than 8 hours per day. ${ }^{12}$

Similarly, in a study in India by Sindhuja et.al. ${ }^{13}$ regarding the clinical profile $37.80 \%$ had URTI Symptoms $15.75 \%$ had a systemic illness, and 8 patients $(6.29 \%)$ had conjunctival congestion. $3 / 8$ patients had developed conjunctival congestion before the manifestation of definite COVID-19 symptoms. In our study, the most common symptom was dyspnoea followed by fever and cough. Only nine patients out of 238 patients had conjunctival congestion which is almost similar to the study by Sindhuja et.al. done in India.

\section{Limitation of the study}

As this study was limited to the in-hospital clinical courses only and follow-up detail were not taken into consideration, thus information on slipcase was not reported.

\section{Acknowledgment}

The authors acknowledge the COVID-19 management team Consisting of the department of anesthesia, Internal Medicine, Microbiology, IT department, medical Record department, and hospital administration who helped in setting up a dedicated facility for COVID-19 Positive patients and their management protocol.

\section{REFERENCES}

1. Huang C, wang y, Lix Ren L, Zhoo J Hug et. al. Clinical feature of patients infected with 2019 novel coronavirus in Wuhan, China, Lancet 2020;395:497-506.

2. Wan Y, Shang J, Graham R, Baric RS, LI F. Receptor recognition by novel coronavirus from Wuhan; an analysis based on decade-long structure studies of SARS, coronavirus J viro 12020;94:e00127-e220. $\underline{\text { Crossref }}$

3. Venkatesan P. The changing demographics of COVID-19. The Lancet Respiratory Medicine. 2020;8:E95. Crossref

4. Xu X, Chen P, Wang J, Feng J, Zhou H, Li X, Zhong W, Hao P. Evolution of the novel coronavirus from the ongoing Wuhan outbreak and modeling of its spike protein for risk of human transmission. Sci China Life Sci. 2020;63(3):457-60. $\underline{\text { Crossref }}$

5. Kopel J, Perisetti A, Roghani A, Aziz M, Gajendran M, Goyal H. Racial and Gender-Based Differences in COVID-19. Front Public Health. 2020;8:418. Crossref

6. Nuzzi R, Carucci LL, Tripoli F. COVID-19 and ocular implications: an update. J Ophthalmic Inflamm Infect. 2020;10(1):20. Crossref

7. Sun Y, Liu L, Pan M. Mechanism of the action between the SARSCOV S240 Protein and the ACE 2 receptor in eyes. Int J Ophthalmol. 2006;6:783-6.

8. Soni SL, Kajal K, Yaddanapudi LN, Malhotra P, Puri GD, Bhalla A, et al. Demographic \& clinical profile of patients with COVID-19 at a tertiary care hospital in north India. Indian J Med Res. 2020. $\underline{\text { Crossref }}$
9. Agrawal H, Das N, Nathani S, Saha S, Saini S, Kakar SS, Roy P. An Assessment on Impact of COVID-19 Infection in a Gender Specific Manner. Stem Cell Rev Rep. 2021;17(1):94-112. $\underline{\text { Crossref }}$

10. Verma A, Patyal A, Mathur M, Choudhary S, Mathur N. Sociodemographic and clinical characteristics associated with COVID mortality among hospitalized patients in Rajasthan: A retrospective observational study. J Family Med Prim Care. 2021;10(9):3319-24. $\underline{\text { Crossref }}$

11. Chen L, Deng C, Chen X, Zhang X, Chen B, Yu H, et al. Ocular manifestations and clinical characteristics of 535 cases of COVID-19 in Wuhan, China: a cross-sectional study. Acta Ophthalmol. 2020;98(8):e951-9. Crossref

12. Maragakis LL. Eye Protection and the Risk of Coronavirus Disease 2019: Does Wearing Eye Protection Mitigate Risk in Public, NonHealth Care Settings? JAMA Ophthalmol. 2020;138(11):1199-200. Crossref

13. Sindhuja K, Lomi N, Asif MI, Tandon R. Clinical profile and prevalence of conjunctivitis in mild COVID-19 patients in a tertiary care COVID-19 hospital: A retrospective cross-sectional study. Indian J Ophthalmol. 2020;68(8):1546-50. Crossref 